\title{
Principales causas de deserción estudiantil y técnicas aplicadas para su prevención desde la gestión en el Colegio Nocturno La Unión y en el Colegio Nacional Virtual Marco Tulio Salazar sede en el cantón de La Unión
}

\author{
Main causes of dropout student and applied techniques for prevention from managing in the \\ Night School of the Union and the National School Virtual Marco Tulio Salazar \\ headquarters in the canton of La Union
}

\author{
Leonardo Herrera Vargas ${ }^{1}$ \\ Universidad de Costa Rica \\ leonardo.herrera @ucr.ac.cr
}

Recibido 06 noviembre 2012 • Aceptado 06 diciembre 2012 • Corregido 12 de diciembre 2012

Resumen. El presente artículo corresponde a una investigación realizada en el Colegio Nocturno La Unión y en el Colegio Nacional Virtual Marco Tulio Salazar, sede en el cantón de La Unión. La investigación realizada es de tipo descriptivo, debido a la información recopilada sobre cada una de las categorías de análisis definidas y su enfoque es cuantitativo, por la búsqueda de generalidades que se dan en la población nocturna con respecto a la deserción estudiantil, de modo que se profundiza en el objetivo de la investigación por medio de los siguientes objetivos: Identificar el porcentaje de deserción estudiantil, por nivel y por género, de los últimos cinco años, determinar los factores socioculturales, pedagógicos, económicos y familiares que causan deserción estudiantil, describir las estrategias que actualmente se implementan desde la administración para disminuir la deserción estudiantil en el Colegio Nocturno La Unión y en el Colegio Nacional Virtual Marco Tulio Salazar, sede en el cantón de La Unión. Los resultados obtenidos permitieron fundamentar el desarrollo de una propuesta con el objetivo de enfrentar la deserción estudiantil desde la administración de la educación.

Palabras claves. Educación, Administración, Administración de la Educación, Deserción, Factores,

\footnotetext{
Máster en Ciencias de la Educación con énfasis en Administración Educativa de la Universidad de Costa Rica (UCR). Licenciado en enseñanza de la Física (UCR). Bachiller en enseñanza de las Ciencias Naturales (UCR) y profesorado en enseñanza de las Ciencias Naturales (UCR). Actualmente se desempeña como docente de la Escuela de Física (UCR), en la Escuela de Estudios Generales (UCR) y también como colaborador del Programa Planetario. Asimismo es integrante de la Sección de Astronomía y Astrofísica, y del Centro de Investigaciones Espaciales (CINESPA) de la Universidad de Costa Rica.
} 
socioculturales, pedagógicos, económicos, familiares.

Abstract. This present article corresponds to investigation conducted in the Night School of the Union and the National School Virtual Marco Tulio Salazar headquarters in the canton of La Union. The research is type descriptive, due the information collected on each of the defined categories of analysis and its focus is quantitative, for the search for generalities that is give in the population, with respect into dropout student, of the mode that deepens in the objective of the investigation by means of the following objectives: Identify the dropout rate by level and by gender, in the last five years, to determine the factors socio-cultural, educational, economic and family causing dropout student, describe the strategies are implemented by the administration to reduce the dropout student in the Night School of the Union and the National School Virtual Marco Tulio Salazar headquarters in the canton of La Union. The results obtained allowed the development the development of a proposal in order to address the drop out student from the educational administration.

Keywords. Education, Administration, Administration of the Education, Dropout, factors, sociocultural, educational, economic, familiar.

\section{Presentación}

Actualmente, la sociedad presenta constantes y acelerados cambios que deben considerarse en las organizaciones educativas. Se tiene como reto el desarrollo de planes y estrategias educativas aptas para llevar a cabo el cumplimiento de la misión y visión de cada una de las organizaciones educativas.

Al analizar la historia de la humanidad, se ha evidenciado que la cultura y los valores se encuentran en una constante evolución, conforme pasa el tiempo, los valores culturales son sustituidos por otros. Al respecto, López (2004) considera que las culturas han experimentado continuas transformaciones:

La historia ha demostrado que las culturas desaparecen y son sustituidas por otras. La dinámica propia de la producción de cultura lleva implícito el germen del cambio pues la transmisión de los valores, pautas del comportamiento, no se da en forma mecánica. (p. 84)

Una de las tareas que le concierne a la educación es la de transmitir valores que identifican a la sociedad en la que se encuentra inmersa, además de las destrezas y los conocimientos necesarios que la sociedad requiere. En este sentido, López (2004) argumenta que "a la educación le corresponde transmitir valores, dotar de los conocimientos y destrezas necesarias para ocupar los diversos cargos de la estructura de la sociedad, así como para la vida en sociedad" (p. 85).

La sociedad, a escala mundial, se encuentra en constante cambio; uno de los principales contribuyentes a esta evolución es la globalización, que permite unir el mundo a través de los medios de comunicación. 
Conforme ha pasado el tiempo los medios de comunicación son mejores, por lo que se permite el intercambio cultural, social y económico de una mejor manera, en donde la educación se encuentra presente $y$, de forma ideal, esta debe evolucionar junto con todos los cambios que presenta la sociedad, con el objetivo de satisfacer las necesidades y contribuir a la evolución.

Al delimitar el globo terrestre en América Latina, y enfocar sus diferentes regiones, se determina que los diversos países presentan problemas similares en el ámbito de la educación entre sí. En donde se enfatiza que los programas de estudio son estáticos, se destina un bajo presupuesto a la educación, hay bajos salarios para los docentes, baja formación en el personal encargado de la docencia, además, de un alto índice de repetición de los educandos. Vásquez (1985) señala los problemas globales de América Latina en la educación en el aspecto económico y la formación que reciben los educadores:

Para América Latina, podemos señalar que los problemas comunes y globales son los siguientes: escaso presupuesto para educación y distribuido en general, en detrimento de la enseñanza media y de la técnica; insuficiencia de maestros con formación de tercer nivel y en permanente "reciclaje", penuria de locales (especialmente en aéreas rurales); baja calidad de la enseñanza, con programas estáticos y enciclopedistas; alto índice de desgranamiento; repetición y selectividad en todos los niveles de sistema educacional; bajos salarios docentes; alto índice en la relación docente/alumno (32/1), discontinuidad de políticas educativas, incorporación acrítica de modelos educacionales. (p. 31)

Tanto de forma mundial, como regional y local, se han logrado identificar graves problemas en el ámbito de la educación, problemas que se deben solucionar lo antes posible para hacer frente a las nuevas necesidades que la sociedad actual afronta.

De acuerdo con la Organización de las Naciones Unidas para la Educación, la Ciencia y la Cultura (UNESCO, 2011), a escala mundial y regional, la deserción escolar es un problema que enfrenta la sociedad en general, en donde la población más afectada es la de bajos recursos económicos, al disminuir la posibilidad de salir de una situación de pobreza e imposibilitando la movilidad social, en conjunto con una serie de factores que interfieren en el aspecto sociocultural, pedagógico, económicos y familiar, que contribuyen en la deserción estudiantil.

El fenómeno de la deserción escolar tiene por consecuencia privar a los niños más vulnerables de posibilidades para su vida futura, cerrando las puertas de una posible salida de su situación de pobreza y mermando el potencial de reforzamiento de la movilidad social que tiene la educación. (p. 54) 
De acuerdo con lo mencionado, la deserción escolar es un problema que enfrenta la administración de cada uno de los centros educativos y desde hace varios años se han implementado diferentes estrategias para hacerle frente. Fenómeno que afecta principalmente a la población con menos recursos económicos, "la exclusión del estudiante del sistema educativo significa la pérdida de la función establecida por el sistema, en torno a la sociedad, como es el brindar mayores oportunidades a la población" (Sánchez, Ugalde, Vargas y Venegas, 1984, p. 24).

La funcionalidad del sistema educativo consiste en brindarle al estudiante las herramientas necesarias en conjunto con valores y humanismo, para que sea parte de una sociedad armoniosa; aunque en la actualidad se le ha dado más importancia a la cantidad de años de escolaridad que a la calidad. Según lo establecido por la UNESCO (2011):

La mayoría de los planes nacionales de educación no dan prioridad suficiente a la resolución del problema de la deserción escolar. Conceden más importancia al aumento de la escolarización y a la mejora de la calidad de la enseñanza, en vez de reforzar las medidas destinadas a mantener a los alumnos en la escuela y hacerlos progresar a lo largo de sus diferentes grados, porque parten del supuesto de que la deserción escolar disminuirá automáticamente a medida que la escolarización de los niños aumenta. Los datos y elementos de información presentados en esta sección ponen en tela de juicio esa hipótesis. (p. 54)

En el contexto nacional, la educación ha presentado grandes retos que han sido superados a lo largo de la historia, como lo es la alfabetización, pues se ha logrado cubrir casi todo el país. Hoy día se presentan nuevos retos, entre ellos, la cobertura a nivel nacional de la secundaria, dado que, a pesar de aumentar considerablemente, no se ha logrado su totalidad y, al mismo tiempo, se encuentra la deserción escolar especialmente en secundaria.

De acuerdo con el Plan de Acción 2003-2015, propuesto por el Ministerio de Educación Pública (MEP, 2002), la educación costarricense tiene como reto la retención y el éxito de los estudiantes en sus respectivos estudios:

La Educación Secundaria continúa siendo un reto para el sistema educativo costarricense, a pesar de que en los últimos años ha venido aumentando al menos su cobertura, no obstante con la masificación de los servicios vienen asociados otros desafíos como son la retención y éxito en este nivel educativo, así como la vinculación de las propuestas curriculares con el mundo del trabajo y la continuidad de estudios superiores. (p. 17) 
Entre los retos más importantes que actualmente enfrenta la educación secundaria, se encuentra el cómo mantener a los estudiantes dentro del sistema educativo, este desafío aumenta conforme incrementa la cobertura escolar.

El Ministerio de Educación Pública (MEP, 2002) en el plan de acción 2003-2015, fundamenta el objetivo de retención de la población estudiantil por medio de diferentes programas y financiamientos económicos:

Brindar mayores oportunidades educativas para el desarrollo de las capacidades humanas, enfatizando en la atención de las poblaciones menos favorecidas, es también una prioridad. Por esta razón, el fortalecimiento de los programas de comedores escolares, transporte estudiantil, becas y bono para la educación, así como la mejor selección de los beneficiarios y la administración eficiente de los recursos, son parte del relanzamiento de la educación. (p. 18)

El MEP, ante la problemática de deserción, exclusión y fracaso escolar, en la propuesta hacia el siglo XXI, enfatiza la atención hacia poblaciones menos favorecidas, fortaleciendo los diferentes programas como lo son las becas de transporte, comedor y bonos para la educación que tienen los centros educativos con el fin de motivar a los estudiantes a estudiar y permanecer en el centro educativo.

Actualmente, la educación establece una serie de retos que son considerados en la Política Educativa hacia el Siglo XXI (MEP, 1994), desde la era de la sostenibilidad se encuentra trabajando, el marco político, económico y social. Entre los objetivos de la educación se encuentra la formación de seres humanos integrales, críticos y, además, como ser integral logre incorporarse a la sociedad que se encuentra en constante evolución.

Desde el punto de vista de la sostenibilidad del recurso humano y el reto de la formación integral del recurso humano que significa, la educación deberá contribuir a formar ciudadanos que puedan pensar en forma crítica y rigurosa, capaces de "aprender a aprender". (p. 5)

De acuerdo con lo considerado en la Política Educativa hacia el Siglo XXI (MEP, 1994), la educación costarricense tiene como reto fomentar en la sociedad de hoy día, una serie de valores y actitudes, necesarios para afrontar la vida, además de contribuir en la disminución de la brecha entre las clases sociales. 
El reto social que significa luchar por la sostenibilidad social y política del país, representa para la educación volver a ser un instrumento eficaz para cerrar la brecha entre las clases sociales, crear nuevas oportunidades de ascenso social y suscitar la participación activa de todos los costarricenses en la solución solidaria de los problemas. La educación asume el reto ético, que fortalece aquellos valores y actitudes que le den a la propia vida, de lo económico y a lo social un sentido altruista, inspirador, incorruptible y humanista. Desde el punto de vista individual, contribuye a asumir el reto relativo al pleno desarrollo de la personalidad de los educandos. (p. 5)

La educación es el medio por el cual una sociedad logra disminuir las brechas entre las clases sociales, al contribuir con el ascenso social.

La educación es un proceso formativo permanente que se encuentra presente a lo largo de toda la vida, constituye un proceso continuo en el que intervienen diferentes entes como la familia, la escuela, el grupo de pares. Cabe destacar que, en este sentido, la misión del educador es la de ser un orientador en el aprendizaje del educando.

Según lo establecido por la Política Educativa hacia el Siglo XXI (MEP, 1994): "el educador debe ser el facilitador, colaborador y orientador del aprendizaje del educando. Por lo tanto, es el responsable de la calidad de la enseñanza junto con el hogar y las autoridades educativas" ( $p$. 8). La educación se considera como "un proceso formativo permanente, cuyo ejercicio es tanto un derecho como un deber inherentes de la persona humana" (MEP, 1994, p. 8).

De acuerdo con las estadísticas suministradas por CONARE (2011), en los últimos años la deserción en el nivel de secundaria ha disminuido, en porcentajes considerables:

En secundaria diurna, la deserción se redujo del 11,6\% en 2006 al 9,5\% en 2009. El sétimo año se mantiene como el momento más problemático de abandono del sistema educativo, aunque se registró una disminución de 20,1\% en 2006 a 16,1\% en 2009. (p. 125)

Es observable, según las estadísticas anteriores, que la deserción en los últimos años ha disminuido considerablemente, aunque hay un alto porcentaje de jóvenes que abandonan el sistema educativo.

\section{El problema de investigación}

El Ministerio de Educación Pública, en los últimos años, por medio de diferentes proyectos se ha preocupado por hacer frente a la deserción escolar. Para el año 2009, los porcentajes 
de deserción disminuyeron en gran escala, evidenciando buenos resultados en sus diferentes proyectos, aunque todavía la deserción representa un porcentaje considerable. De acuerdo con los datos presentados por CONARE (2011), un porcentaje de centros educativos presenta cifras preocupantes, en el aspecto de la deserción:

Al analizar cómo se distribuyen los centros educativos de secundaria según su porcentaje de abandono y reprobación, se encuentra que en el año 2009 apenas el 14,3\% de ellos estaba en un rango inferior al $5 \%$ de abandono y reprobación, mientras que un $6 \%$ equivalente a 47 colegios, correspondía a centros donde más del $20 \%$ de los estudiantes que se matricularon al iniciar el año lectivo abandonaron las aulas o reprobaron el curso. (p. 132)

De acuerdo con CONARE (2011) los datos obtenidos reales de la cantidad de estudiantes que no han logrado concluir sus estudios de educación secundaria en un periodo de diez años, es considerable; por lo que los centros educativos deben afinar y aplicar nuevas estrategias de forma independiente para motivar a los estudiantes a concluir con éxito los estudios.

En los números absolutos, entre 1999 y 2009 un promedio de 35765 alumnos por año fue expulsado del sistema educativo, para un total de 393412 estudiantes a los que no es posible darles seguimiento para comprobar cuántos se reincorporaron a la educación no formal. Estos datos constituyen un llamado de atención sobre la necesidad de mantener, profundizar y afinar las estrategias de retención, tanto por niveles, como por regiones y tipos de centros educativos. (p. 125)

Al observar la cifra de jóvenes que abandonaron el sistema educativo formal en la década señalada, es impactante el alto porcentaje de jóvenes que no logra terminar los estudios de secundaria, lo que significa que algo está pasando en los centros educativos que presentan promociones muy bajas y, a su vez, la deserción es muy alta. "Estos datos revelan serios problemas en algunos centros educativos de secundaria, donde más de la mitad de los alumnos matriculados al inicio del año lectivo de 2009 abandonó los estudios sin finalizarlo" (CONARE, 2011, p. 132).

Uno de los sectores más vulnerables a esta problemática pertenece a los educandos de las instituciones nocturnas del país. Esta población se encuentra formada por una gran cantidad de jóvenes que hacen un serios esfuerzos por permanecer dentro del sistema educativo, aun teniendo un ambiente fuera de la institución muy difícil debido a jornadas de trabajo muy largas, 
además de ser padres de familia. Los datos ofrecidos por CONARE (2011), evidencian que esta población es una de las más vulnerables en la educación media:

Al elaborar un ranking de los cincuenta colegios con mayor porcentaje de abandono, se encontró que el $68 \%$ eran nocturnos. Esto surgiere la necesidad de brindar apoyos especiales a este tipo de instituciones, tomando en cuenta que acogen a una importante cantidad de jóvenes que hacen un esfuerzo por permanecer en el sistema, pero que generalmente enfrentan un ambiente extraescolar difícil, dado que la mayoría de ellos trabajan durante el día y en muchos casos son padres de familia. (p. 132)

La población de los centros educativos nocturnos, en su mayoría, debe hacer frente a gran cantidad de factores que aumentan la posibilidad de desertar de los estudios secundarios, como lo son la incorporación temprana al mercado laboral debido a problemas económicos, que repercuten en condiciones de pobreza y marginalidad.

Tal y como lo señala, CONARE (2011), la población de los colegios nocturnos es una población que se encuentra en alto riesgo de abandonar los estudios debido a la situación económica, por lo que han tenido que incorporarse al mercado laboral en edades muy tempranas, en donde las prioridades se enfatizan en el aspecto laboral y no en el estudio debido a las necesidades que deben enfrentar:

Dos grandes componentes que ayudan a explicar el proceso de exclusión y sus causas. Por un lado están la situación socioeconómica y el contexto familiar de los estudiantes, en particular las condiciones de pobreza y marginalidad, la incorporación temprana al mercado laboral, la armonía familiar y las adicciones, entre otros. Se trata de factores de naturaleza extraescolar, cuyo origen está en el mercado, la comunidad y la familia. (p. 125)

Actualmente, dentro del sistema educativo, algunos de los planes de estudio no suplen algunas de las necesidades de los jóvenes de hoy, además se deben considerar las diferentes modalidades educativas del sistema educativo; en algunos casos, los programas no tienen relación con la realidad cotidiana de los estudiantes, por lo que se induce a la deserción escolar. En relación con el tema Tristán (2003), se refiere a los serios problemas que ha tenido el sistema educativo en promover las destrezas y habilidades básicas que el contexto nacional e internacional demanda para los futuros ciudadanos: 
En efecto, las tasas de deserción y las causas que la provocan son similares a las de diez años atrás. Más aún, el sistema sigue teniendo serios problemas para promover en los estudiantes destrezas y habilidades básicas que hoy demanda el contexto nacional e internacional, especialmente en áreas como las ciencias, el dominio de idiomas y el uso de las nuevas tecnologías de información y comunicación. (p. 116)

El sistema educativo debe reconsiderar la elaboración de programas de estudio específicos para las diferentes modalidades educativas que se imparten en el país, considerando la debida adecuación de los contenidos y contextualización hacia la población que va a estudiar con ellos. Al respecto, Tristán (2003), comenta que los programas que hoy día se utilizan en el sistema educativo, tienen aproximadamente cuarenta años sin recibir cambios a profundidad:

A pesar de los intentos de cambiar programas de estudio, la estructura curricular en secundaria no se ha modificado desde los años setenta y muestra notables desequilibrios entre contenidos y actividades, poca articulación entre ciclos y materias, y una aplicación homogénea y descontextualizada. (p. 116)

Desde la administración de la educación se tiene como reto disminuir la deserción escolar, por lo que se debe considerar el empleo de diferentes estrategias y metodologías, aplicables en los centros educativos, considerando que actualmente el mundo presenta gran diversidad cultural, que cada vez es mayor gracias a la globalización, por medio de la conectividad a escala mundial. La sociedad actualmente se encuentra en una constante evolución sociocultural, al apropiarse de costumbres y valores pertenecientes a otras regiones del mundo. Al respecto, Masís (1989) enfatiza que la educación es un proceso que culmina al cumplir con las necesidades que la sociedad actualmente requiere:

La educación como un proceso de trabajo planificado con objetivo de cumplir con las necesidades que la sociedad presente, busca el desarrollo integral del individuo a partir de objetivos preestablecidos, que conduce a la adaptación y transformación de las condiciones económicas, políticas y sociales. Donde el planeamiento es el planteo y organización de los recursos humanos, materiales y financieros para cumplir con determinados objetivos. (p. 12) 
Un problema que presenta la educación hoy y que aqueja a la administración de la educación es la deserción, problema al cual se le debe buscar solución. Por lo tanto, la presente investigación identifica las estrategias que se desarrollan para hacer frente a la deserción en el cantón de La Unión, en la modalidad nocturna. "La deserción escolar no es, en efecto, más que un producto de nuestro sistema escolar y una expresión de las fallas de nuestra sociedad. Reflejo estructural de la economía liberal, el sistema escolar es competitivo, selectivo" (López, 2004, p. 88).

De acuerdo con datos del Ministerio de Educación Pública, en el año 2010, la modalidad nocturna académica fue la que presentó el porcentaje más alto con respecto a la deserción estudiantil. Estos datos se reflejan en las siguientes gráficas.

En la Gráfica 1, se ejemplifican los porcentajes del ciclo lectivo 2010 en el nivel nacional, al confrontar el porcentaje de población estudiantil que inicia el ciclo lectivo en comparación con los porcentaje estudiantil que terminaron el curso lectivo y los que desertaron, considerando como un solo la educación pública, privada y privada subvencionada.

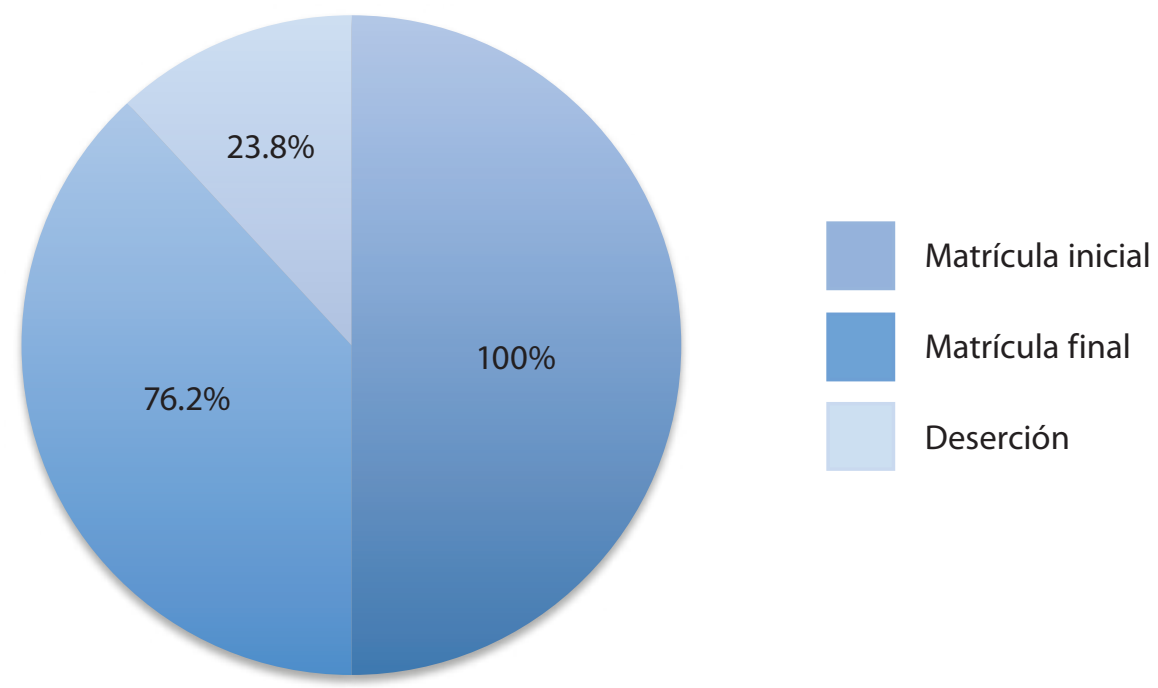

Figura 1. Educación nocturna académica en el nivel nacional, 2010

Fuente: CONARE, 2010

En la gráfica anterior se evidencia el alto porcentaje de estudiantes que desertó del sistema educativo académico nocturno en el 2010, cifra que es preocupante desde el punto de vista de la administración de la educación. 
La Gráfica 2 refleja los porcentajes de la población estudiantil que ingresó en el ciclo lectivo 2010, a la modalidad nocturna en la Dirección Regional de Educación de Cartago, con respecto de la cantidad de estudiantes que logran terminar el periodo lectivo y los que desertan del sistema educativo.

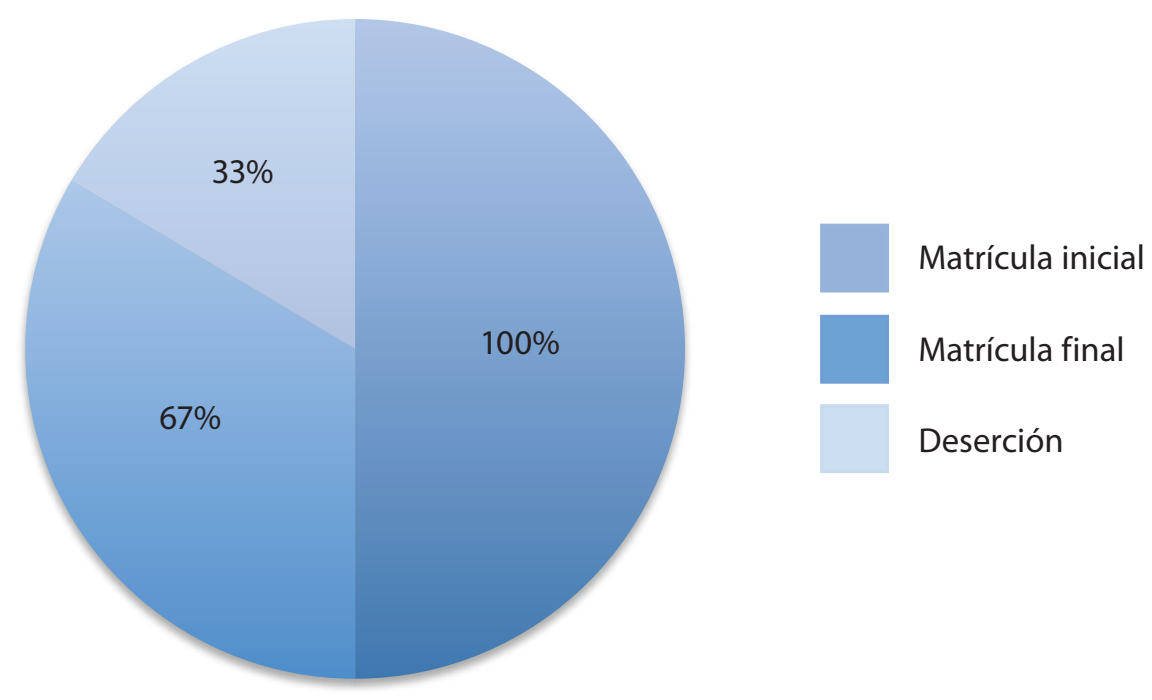

Figura 2. Dirección Regional de Educación de Cartago Educación Nocturna Académica, 2010

Fuente: CONARE, 2010

En esta gráfica se representa la Dirección Regional de Cartago, en educación nocturna académica, del año 2010, evidenciando el alto porcentaje de deserción que se dio en ese año, cifra que es alarmante vista desde la administración de la educación.

Por lo anterior, el presente trabajo de investigación se realiza en dos instituciones seleccionadas, de forma aleatoria, pertenecientes a la dirección Regional de Educación de Cartago, específicamente el Colegio Nocturno La Unión y el Colegio Virtual Marco Tulio Salazar, sede en el cantón de La Unión, con la finalidad de determinar las causas que inducen a la población estudiantil a abandonar el sistema educativo nocturno, considerando que la mayoría de estudiantes de ambos centros educativos han desertado del sistema educativo diurno por diferentes razones y se han incorporado al sistema educativo nocturno por lo que su edad es mayor que la de estudiantes que ha tenido una continuidad en sus estudios desde el inicio de la primaria, así como los mecanismos empleados para su prevención, desde la gestión de la administración de la educación. 
En ese sentido, se realizó una investigación que cubrió los siguientes objetivos:

1. Identificar el porcentaje de deserción estudiantil, por nivel y por género, de los últimos cinco años en el Colegio Nocturno La Unión y en el Colegio Nacional Virtual Marco Tulio Salazar, sede en el cantón de La Unión.

2. Determinar los factores socioculturales, pedagógicos, económicos y familiares que causan deserción estudiantil en el Colegio Nocturno La Unión y en el Colegio Nacional Virtual Marco Tulio Salazar, sede en el cantón de La Unión.

3. Describir las estrategias que actualmente se implementan desde la administración para disminuir la deserción estudiantil en el Colegio Nocturno La Unión y el Colegio Nacional Virtual Marco Tulio Salazar, sede en el cantón de La Unión.

\section{Referente teórico}

\section{Educación, conceptualización}

La educación es una ciencia, que adquiere sus atribuciones gracias a la pedagogía; "el objeto de estudio de la pedagogía es la educación, en forma más precisa la práctica de la educación" (Ordóñez, 1999, p. 141). El objeto de estudio de la educación es la población estudiantil, a quien se le transmiten los conocimientos que la sociedad requiere que conozca, con el objetivo de que, a largo plazo, logre incorporarse a las actividades laborales ofrecidas por la sociedad.

“La palabra 'educación' viene del término latino educare que, a su vez, forma el verbo educere que tiene dos raíces: ex (afuera) y ducere (llevar, conducir). En otras palabras, el término educación significa desde la perspectiva etimológica, conducir afuera" (Ordóñez, 1999, p. 136).

En Costa Rica, a la educación en el nivel de secundaria en los últimos años se le ha dado gran prioridad, al incrementar la cobertura y calidad, con el objetivo de formar jóvenes integrales a quienes se les facilite ingresar a una educación superior o al mundo laboral.

\section{Administración}

Desde la antigüedad la administración se encontró presente en todos los quehaceres de la humanidad, con las demandas de su entorno social, económico y cultural, en donde se ha demostrado la gran capacidad administrativa que tiene el ser humano para poder enfrentar una gran cantidad de retos y lograr todo el acervo de conocimiento acumulado hasta el día de hoy, además de todo el legado arquitectónico que se conserva hasta el día de hoy. En ese sentido, 
Zeledón (2001) hace una breve reseña histórica de lo que ha sido la administración desde los principios de la humanidad en civilizaciones muy antiguas:

La historia ha sido fiel testigo de las diversas maneras en que el ser humano se ha organizado para enfrentar los retos que le demanda su entorno social, económico y cultural. Desde la antigüedad, por ejemplo, las grandes construcciones erigidas en Egipto, Mesopotamia y Siria, revelan la existencia de dirigentes con capacidad para planear y guiar los esfuerzos de millares de trabajadores, en la edificación de magnificas obras, que aún hoy perduran. (p. 23)

En la era del renacimiento se da el surgimiento de todas las ciencias, tanto naturales como sociales y la administración que siempre se encontró presente en los diferentes quehaceres de la humanidad.

\section{Administración de la educación}

La administración de la educación es una disciplina que se origina de la administración general, además de una serie de recursos que la caracterizan, Arroyo (2010) detalla el objetivo de la administración de la educación:

La Administración de la Educación, pretende organizar el trabajo de un conjunto de personas, docentes, administrativos, docentes administrativos, y el manejo de un conjunto de recursos físicos, financieros, tecnológicos y pedagógicos entre otros, para cumplir con el currículo definido por la sociedad. (p. 6)

La administración de la educación es una disciplina reciente que fundamenta sus bases teóricas y credenciales al nutrirse de otras disciplinas, de acuerdo con la fundamentación de Garbanzo (2011), con respecto a las organizaciones educativas.

La Administración de la Educación se nutre de distintas ramas disciplinares, tales como: la Teoría de la Educación, la Administración pública y empresarial, la Psicología y la Sociología, entre otras, elaborando su propio constructo de conocimientos y prácticas, cuyo eje estratégico lo determina el rol que juegan las organizaciones educativas en la sociedad. (p. 26) 
La teoría de la educación, es uno de los principales contribuyentes de la gestión de acuerdo con, Garbanzo (2011):

La teoría de la administración como disciplina que nutre la gestión educativa, desde que se inicia la sistematización de la Administración de la Educación se adopta en forma generalizada, careciendo de adopciones propias del campo y contexto según la sociedad a la cual se inserta. (p. 14)

La administración de la educación es una disciplina que tiene como fin la conducción de las organizaciones educativas, desde lo administrativo a lo curricular, en donde se reflejen las necesidades de la sociedad en la cual se encuentra la institución; el administrador de la educación, por medio de diferentes estrategias administrativas, vela por la satisfacción de las necesidades que la sociedad presenta.

\section{Deserción}

El concepto de deserción escolar presenta diferentes enfoques como por ejemplo: "Se ha definido la deserción escolar como el desinterés de la población estudiantil por el estudio, a causa de problemas socioculturales y emocionales que viven" (González, 2010, p. 15). Se entiende que el estudiantado que ha desertado del sistema educativo, es aquel que abandona el sistema educativo formal, no se traslada a otra institución formal después de iniciar el curso lectivo.

La deserción estudiantil se clasifica en dos tipos, la primera se le conoce como deserción académica y es cuando el estudiantado no continúa con el proceso educativo debido a las exigencias que el sistema educativo les impone; y el segundo tipo de deserción se debe por desmotivación que tiene una gran influencia el ambiente además de no existir un modelo que motive para continuar con los estudios por parte de sus familiares o pares. Petit, Calimán y Carballo (2009), fundamentan los dos tipos de deserción:

Existen dos tipos de deserciones: la académica, que se presenta cuando los estudiantes no continúan en el proceso educativo, porque no puede superar las exigencias que este les plantea, y la deserción por desmotivación, la cual ocurre cuando no existe un patrón de modelo de continuidad académica en el entorno del mismo, acompañado de factores ambientales, familiares, económicos y emocionales, que propician directamente la desmotivación. (p. 339) 
Muchos estudiantes desertan del sistema educativo debido a la desmotivación como consecuencia del poco apoyo recibido de sus padres y madres de familia, en lo que se refiere a materiales de apoyo, que en muchas ocasiones se da por problemas económicos, aunque hay un número de familias que no se debe a conflictos económicos sino una falta de cultura.

\section{Referentes metodológicos}

La investigación se define de tipo descriptivo; por lo que se recopila información sobre cada una de las categorías de análisis definidas, de forma independiente, y luego se entrelaza la información obtenida con el fin de analizar el fenómeno de interés. Hernández, Fernández, y Baptista (2006) señalan que "los estudios descriptivos miden de forma independiente las variables aunque pueden integrarse las mediciones de cada una de dichas variables" (p. 60).

El enfoque de la presente investigación es cuantitativo, por la búsqueda de generalidades que se dan en la población estudiantil nocturna con respecto a la deserción escolar y al generar teorías que permiten comprender cómo factores socioculturales, pedagógicos, económicos y familiares inciden en ella.

En esta investigación se aplica una serie de cuestionarios dirigidos al personal docente y administrativo, así como a la dirección del centro educativo y estudiantes de $7^{\circ}$ año que tuvieron la intención de desertar del sistema educativo en el ciclo lectivo 2011, por medio de los cuales se logra obtener la información significativa de los factores que inciden en la deserción estudiantil.

En el Colegio Nocturno La Unión, el cuestionario se aplicó a nueve docentes, cuatro miembros del personal administrativo que interactuaron de forma directa con los veintisiete estudiantes, actualmente de octavo año, que intentaron desertar de la institución en el ciclo lectivo 2011, cuando cursaban sétimo año y al profesional en administración de la educación a cargo de la dirección de la institución, de acuerdo con la información suministrada por el centro educativo.

En el Colegio Nacional Virtual Marco Tulio Salazar sede en el cantón de La Unión, el cuestionario se aplicó al profesional en administración de la educación de la sede, cinco docentes, un miembro del personal administrativo, quienes interactuaron de forma directa con los dieciséis estudiantes, actualmente de octavo año, que intentaron desertar de la institución en el ciclo lectivo 2011, cuando cursaban sétimo año, de acuerdo con la información suministrada por la dirección del centro educativo.

El desarrollo de esta investigación desde la especificidad de sus categorías de análisis, de acuerdo con sus objetivos se presenta en forma detallada a continuación. 
Tabla 1

Operacionalización metodológica de la investigación

Objetivo específico

Identificar el porcentaje de deserción estudiantil, por nivel y por género, de los últimos cinco años en el Colegio Nocturno La Unión y en el Colegio Nacional Virtual Marco Tulio Salazar, sede en el cantón de La Unión.

Categoría de análisis

Porcentaje de deserción por nivel y por género.

Definición conceptual

González (2010, p. 15) define la deserción escolar como "el desinterés de los alumnos por el estudio, a causa de problemas socioculturales y emocionales que viven".

Nivel corresponde al grado académico que se encuentra cursando un estudiante.

Género se clasifica como masculino o femenino.

Se define porcentaje de deserción a la proporción de alumnos que abandonan el sistema educativo.

Definición operacional Para efectos de este trabajo se define como la cantidad de estudiantes que han desertado por nivel y por hombres y mujeres, en los últimos cinco años en las instituciones en estudio.

Indicadores

Aumento o disminución en la cantidad de estudiantes, durante el ciclo lectivo, en los diferentes niveles.

Instrumentalización

A partir de información brindada en los centros educativos en forma digital e impresa.

Objetivo específico

Determinar los factores socioculturales, pedagógicos, económicos y familiares que causan deserción estudiantil en el Colegio Nocturno La Unión y en el Colegio Nacional Virtual Marco Tulio Salazar, sede en el cantón de La Unión.

Categoría de análisis

Factores que inciden en la deserción en el Colegio Nocturno La Unión y Colegio Virtual Marco Tulio Salazar.

Definición conceptual

En la deserción escolar intervienen una serie de factores y razones descritas por (Ruiz, 2006, p. 26): problemas económicos familiares, falta de interés de los padres en el estudio de sus hijos, ausencia de interés del propio estudiante por buenos rendimientos, recargo de temas en los programas de las asignaturas, exámenes memorísticos, ausentismo de profesores, pérdida de lecciones, carencia de técnicas de estudio, problemas de disciplina, falta de orientación, escasez de talleres, laboratorios, bibliotecas, desmotivación de los profesores y problemas de los alumnos con los profesores.

Factores socioculturales, descritos por (Ruiz, 2006, p. 43). El estudiante con rendimiento apenas regular o que fracasa escolarmente sufre en su autoestima y en la valoración de su pertenencia al sistema educativo.

Factores pedagógicos, descritos por (Ruiz, 2006, p. 54). Una de las principales razones que aducen los estudiantes para su deserción es la falta de atractivo de la educación, y eso está ligado a su valoración de la misma como instrumento para su vida. 
Factores económicos, de acuerdo con (Arguedas y Jiménez, 2007, p. 8), fundamenta el concepto de pobreza por medio de la referencia de MacKinney et ál., (2006). La pobreza no solo significa limitaciones en lo económico y material, sino que es frecuente que se acompañe por desempleo, depresión, desesperanza, violencia y estrés.

Factores familiares, Al respecto (Ruiz, 2006, p. 43). Elementos que pueden empujar hacia su deserción. La ausencia de apoyo familiar, la debilidad en las acciones de retención que posea la institución escolar, la presión por trabajar, la ausencia de atractivo que posea la institución escolar, la presión por trabajar. (p. 43)

Para efectos de la investigación, las causas que provocan que los alumnos abandonen el sistema educativo se dividirán en aspectos socioculturales, pedagógicos, económicos y familiares.

Los factores socioculturales: son todos aquellos hechos sociales que influyen negativamente en los mismos integrantes de la sociedad, causando en los estudiantes el deseo de desertar del sistema educativo.

Factores pedagógicos: son los indicadores que se presentan al desarrollar el proceso educativo y además, la falta de adecuación de los diferentes temas estudiados con respecto a la vida cotidiana.

Factores económicos: Es una serie de indicadores como lo es el desempleo, depresión, desesperanza, violencia y estrés, que contribuyen en la deserción estudiantil.

Factores familiares: Son los indicadores referentes desde la influencia de la familia, hacia el apoyo que se les brinda a los estudiantes y por ende desertan del sistema educativo.

Indicadores

Factores socioculturales: Falta de trabajo en conjunto de la institución y los padres de familia. Falta de apoyo de la institución hacia el estudiante. Falta de apoyo del estudiante por parte de su familia. Cuadros depresivos. Falta de pertenencia a la institución.

Factores extraescolares. Factores intraescolares. Como lo son consumo de alcohol, drogas, violencia.

Factores pedagógicos: Poca relación entre los temas de estudio con la vida cotidiana. Problemas de conducta. Métodos de enseñanza poco claros. Poca adaptación del currículum a las características propias de la sociedad. Deficiencia en la capacitación del docente. Poca relación entre profesor y alumno. Poco sentido al colegio por parte de los jóvenes. Falta de orientación del joven por la institución. Dedicación de mucho tiempo por parte de los jóvenes a actividades fuera de la escuela. Desactualización de los programas de estudio a nivel nacional.

Factores económicos: Bajos ingresos económicos, entre ellos desempleo, desesperanza, estrés. Limitaciones materiales. Problemas de salud, aprendizaje. Dificultad para trasladarse a la escuela. 
Instrumentalización

Objetivo específico

Categoría de análisis

Definición conceptual

Definición operacional

Indicadores

Instrumentalización
Factores familiares: Adscripción temprana de los jóvenes al mundo del trabajo. Poca motivación familiar para que el joven continúe con los estudios. Ausencia del apoyo familiar.

Poca comunicación entre padres e hijos. Poca visión de los padres hacia el futuro de sus hijos.

Cuestionarios dirigidos al personal docente y administrativo, estudiantes y director.

Describir las estrategias que actualmente se implementan desde la administración para disminuir la deserción estudiantil en el Colegio Nocturno La Unión y el Colegio Nacional Virtual Marco Tulio Salazar, sede en el cantón de La Unión.

Estrategias implementadas por la administración del Colegio Nocturno La Unión y el Colegio Nacional Virtual Marco Tulio Salazar, sede en el cantón de La Unión. Para disminuir la deserción estudiantil.

Al establecerse las estrategias para enfrentar la deserción estudiantil, estas se definen de acuerdo con Venegas (1995, p 208-209)

Las estrategias en la planificación de la educación existen para mejorar el servicio educativo y desarrollar todo el potencial que posee cada uno de los miembros de la comunidad educativo.

Las estrategias conducen al análisis de las fortalezas y debilidades propias o internas de cada organización educativa, así como oportunidades y amenazas del entorno (externas) que pueden afectar positiva o negativamente a la organización.

Mecanismos que les permiten a las instituciones; Colegio Nocturno La Unión y el Colegio Nacional Virtual Marco Tulio Salazar, sede en el cantón de La Unión. Enfrentar la deserción estudiantil, como por ejemplo las becas de FONABE y el Programa Avancemos.

Ayuda económica a los estudiantes de pocos recursos por medio de diferentes programas que ofrece el gobierno y el MEP. Creación de aéreas recreativas por medio de las cuales los estudiantes pueden distraerse. Formación de grupos de edades homogéneas.

Cuestionarios dirigidos al personal docente y administrativo, estudiantes y director.

Fuente: Herrera, 2012. Elaboración propia para la investigación.

\section{Instrumentalización}

Con el objetivo de recopilar la información necesaria para llevar a cabo la investigación se diseñan y aplican tres cuestionarios de la siguiente manera el primero al personal docente y administrativo, el secundo a los profesionales en administración de la educación en llos centros educativos y el tercero a los estudiantes que tuvieron intención de desertar del sistema educativo al cursar el nivel de sétimo año en el ciclo lectivo 2011, de los centros educativos seleccionados. 
Los instrumentos aplicados se dividen en dos partes, en la primera parte, se identifican los factores que inciden en la deserción estudiantil, en ella se subclasifican los factores socioculturales, factores pedagógicos, factores económicos, factores familiares, cada uno de los factores se encuentran formados por sus respectivos indicadores, de los cuales se les asignan cinco categorías, siempre, casi siempre, algunas veces, casi nunca y nunca, el entrevistado seleccionara la opción que mejor considere de acuerdo con la influencia que tienen los indicadores con respecto a la deserción estudiantil, en la segunda parte, se identifican las estrategias implementadas por la administración del centro educativo para disminuir la deserción estudiantil con sus respectivos indicadores, de los cuales se les asigna tres categorías, siempre, a veces y nunca, el entrevistado seleccionará la opción que mejor considere según la influencia que tienen los indicadores propuestos por la administración del centro educativo para enfrentar la deserción estudiantil.

\section{Análisis de la información}

A continuación se expresa el análisis de los datos recopilados para efectos de la investigación, la cual estudia las principales causas que propician deserción estudiantil en el Colegio Nocturno La Unión y en el Colegio Nacional Virtual Marco Tulio Salazar, sede en el cantón de La Unión; además, de las estrategias implementadas por la administración para su prevención en ambas instituciones, pertenecientes al circuito 09 de la Dirección Regional de Educación de Cartago.

La información se recopiló por medio de visitas, por parte del investigador, a los centros educativos objeto de estudio con la finalidad de obtener estadísticas acerca de las tasas de deserción estudiantil, así como por medio de un cuestionario aplicado a estudiantes de octavo año de ambos centros educativos, quienes en el 2011, cursando el sétimo año, tuvieron la intención de abandonar los estudios antes de concluir el curso lectivo. De igual manera, se aplicó un cuestionario a las personas que ejercen la dirección y al personal docente y administrativo de ambas organizaciones, quienes en el ciclo lectivo 2011 tuvieron a su cargo a los estudiantes de sétimo año, que actualmente cursan octavo año.

\section{Información referente al Colegio Nocturno La Unión.}

\section{Tasa de deserción por nivel y género}

A partir de las estadísticas precedentes, se observa que, en el Colegio Nocturno La Unión, en el período comprendido entre los años 2007 y 2011, se han dado altos índices de deserción en los diferentes niveles escolares. En el nivel de sétimo, estos han oscilado entre un 59,4\% y un $49 \%$, lo que muestra por una parte, que este es el nivel en el cual se dan las mayores tasas 
de abandono de la población estudiantil y, por otra, la necesidad de aumentar los esfuerzos que se emprenden en el centro educativo para conocer las causas de este fenómeno y dar una respuesta a esta problemática que afecta a tantas familias. Ante esa situación, se decidió, para efectos de este estudio, trabajar con el nivel de sétimo año, pues los diferentes datos presentados son claros al indicar que es urgente disminuir las tasas de deserción estudiantil, las cuales reflejan que, principalmente, son los hombres quienes abandonan las aulas con respecto a las mujeres.

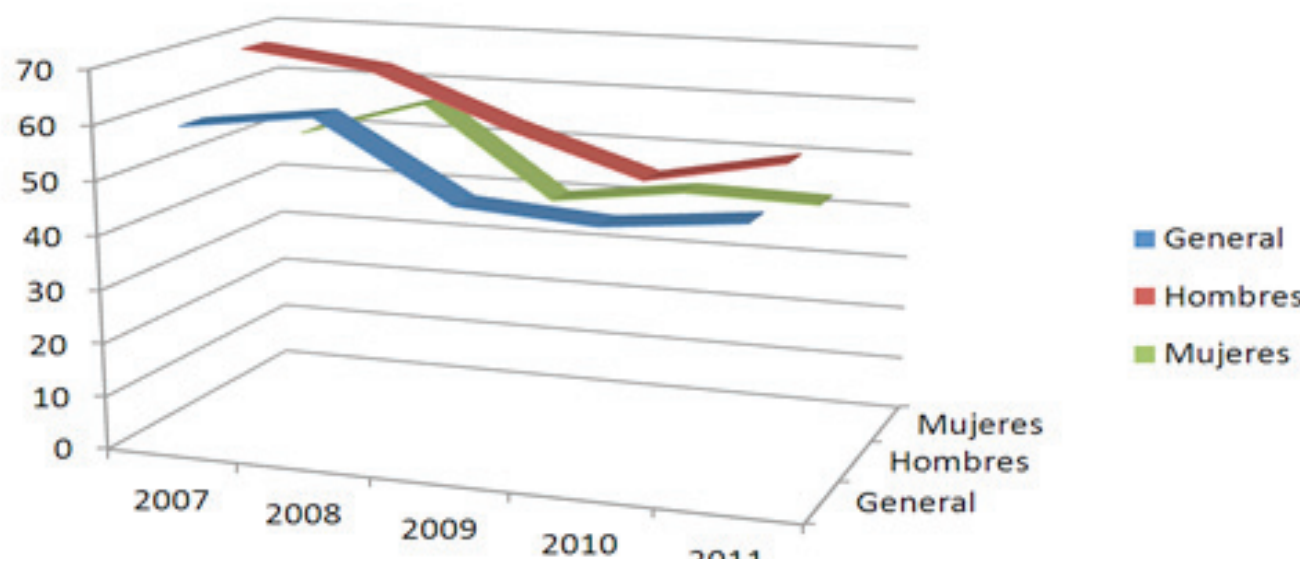

Figura 3. Deserción estudiantil de $7^{\circ}$ año, por género, del periodo 2007-2011, en el Colegio Nocturno La Unión Fuente: Herrera, 2012. Elaboración a partir de información suministrada en el Colegio Nocturno La Unión.

Como se observa en la Gráfica 3, es necesario continuar incrementando los esfuerzos que se realizan entre todos los miembros de la comunidad educativa para disminuir las tasas de deserción escolar que se presentan en el Colegio Nocturno La Unión. Así, desde la administración del centro educativo, es esencial el acompañamiento que se brinda para poner en marcha estrategias que permitan reducir la cantidad de estudiantes que abandonan la institución en los diferentes niveles y, sobre todo, en sétimo año de la educación secundaria, por lo que conviene conocer el origen de este problema, de manera que se desarrollen mecanismos efectivos para contrarrestarlo. 


\section{Factores que inciden en la deserción estudiantil}

\section{Factores socioculturales}

Al comparar las opiniones brindadas por los diferentes participantes en la investigación, con respecto a los principales motivos socioculturales que provocan deserción estudiantil en el Colegio Nocturno La Unión, se observa que las respuestas coinciden al señalar como factores claves: la poca interacción de los padres y madres de familia con el personal docentes de su hijo o hija, y el desinterés por parte de los estudiantes hacia los estudios.

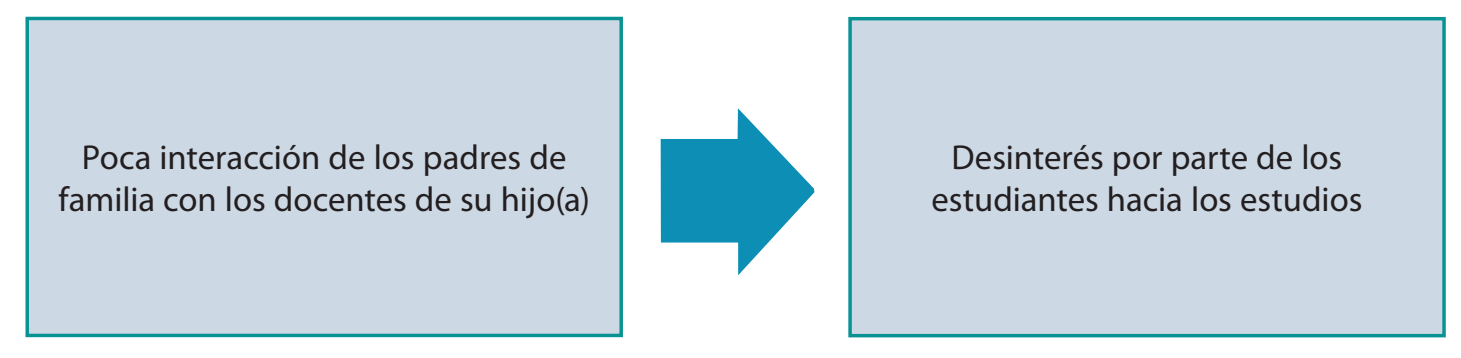

Figura 4. Causas socioculturales de deserción estudiantil según personal docente y administrativo, estudiantes y director, Colegio Nocturno La Unión, año 2012

Fuente: Herrera, 2012. Elaboración a partir de información suministrada en el Colegio Nocturno La Unión.

Los datos obtenidos en el estudio, evidencian lo planteado por Richards (2006), citado por Arguedas y Jiménez (2007), al indicar que:

En algunos casos, las instituciones no responden a las necesidades de las y los estudiantes y sus familiares, en otros son las familias las que no apoyan el trabajo formativo desplegado por la escuela, sobre todo en el ámbito de la disciplina, lo que facilita el desarrollo de conductas transgresoras y de negligencia escolar por parte de los y las jóvenes. (p. 7)

En cuanto a la causas poca interacción de los padres y madres de familia con el personal docente de la población estudiantil, muchos de los estudiantes de la presente investigación no tienen apoyo de sus padres, pues no viven con ellos debido a que tienen su propia familia o se han independizado.

Es necesario que, desde la dirección del centro educativo y con la participación de la comunidad educativa, se gestione la organización de talleres que sensibilicen a la población estudiantil sobre el consumo de drogas, de alcohol y las conductas violentas, por medio de especialistas en el campo de la educación; de manera que se inste a los estudiantes a no caer 
en los diferentes vicios presentes en la sociedad. En este sentido, cuando los jóvenes toman conciencia acerca de los problemas que los pueden afectar y, llegado el caso, cuentan con el apoyo familiar e institucional requerido para hacerles frente, su comportamiento y rendimiento en el centro educativo se verán beneficiados.

\section{Factores pedagógicos}

De acuerdo con las opiniones brindadas por los diferentes participantes en el estudio, con respecto a los principales motivos pedagógicos que influyen en la deserción estudiantil en el Colegio Nocturno La Unión, se observa que las respuestas coinciden al señalar como factores claves, los problemas de aprendizaje por parte de los estudiantes, la descontextualización del currículo escolar y la falta de tiempo por parte de la población estudiantil para actividades curriculares y extracurriculares.

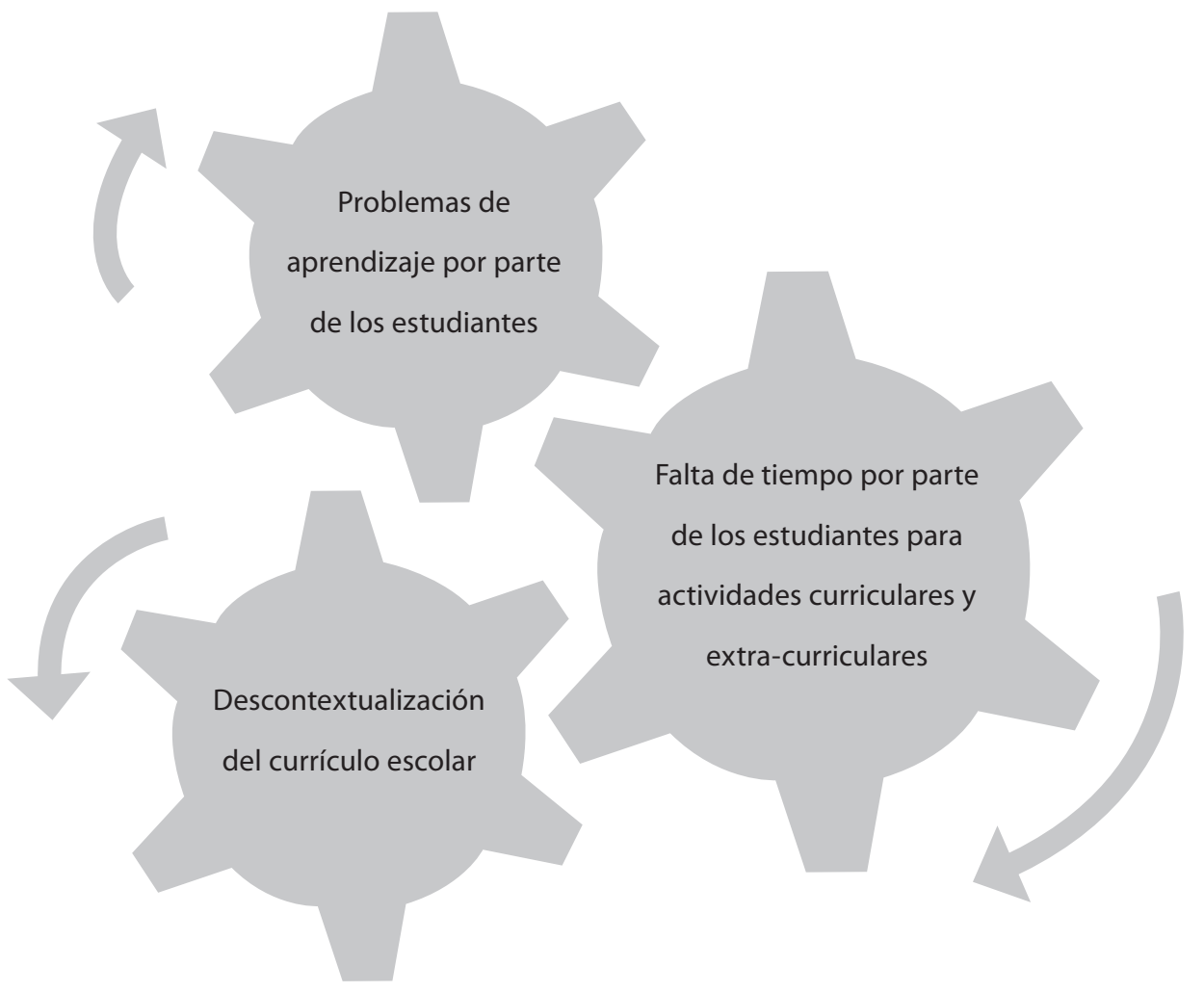

Figura 5. Factores pedagógicos asociados a la deserción estudiantil según personal docente y administrativo, estudiantes y director, Colegio Nocturno La Unión, año 2012

Fuente: Herrera, 2012. Elaboración a partir de información suministrada en el Colegio Nocturno La Unión. 
El profesional en administración de la educación, junto con el personal docente, deben desarrollar una propuesta pedagógica en la que se enfatice en el atractivo y la relación que tienen los temas estudiados en el centro educativo con el diario vivir de los estudiantes, enfocada en los objetivos de la educación, para satisfacer las necesidades de la comunidad en la que se encuentra la institución, siempre considerando la calidad de la educación. En este sentido, Álvarez y Topete (1998) indican que la calidad de la educación:

Está asociada con la capacidad tanto de las instituciones educativas, como de los individuos formados en su seno de satisfacer los requerimientos del desarrollo económico, político y social de la comunidad a la que están integrados. (p. 15)

Desde la administración de la educación, se deben desarrollar diferentes estrategias que evidencien a los padres y madres de los educandos y a la población estudiantil en general, la importancia de la educación para su futura vida y además de la importancia de mantener un buen nivel de calidad en la educación.

\section{Factores económicos}

Las opiniones brindadas por los diferentes participantes en el estudio, con respecto a los principales motivos económicos que determinan la deserción estudiantil en el Colegio Nocturno La Unión, al comparar las respuestas se observa que coinciden al señalar como indicadores claves: los bajos ingresos económicos del núcleo familiar y el estrés que enfrentan los estudiantes.

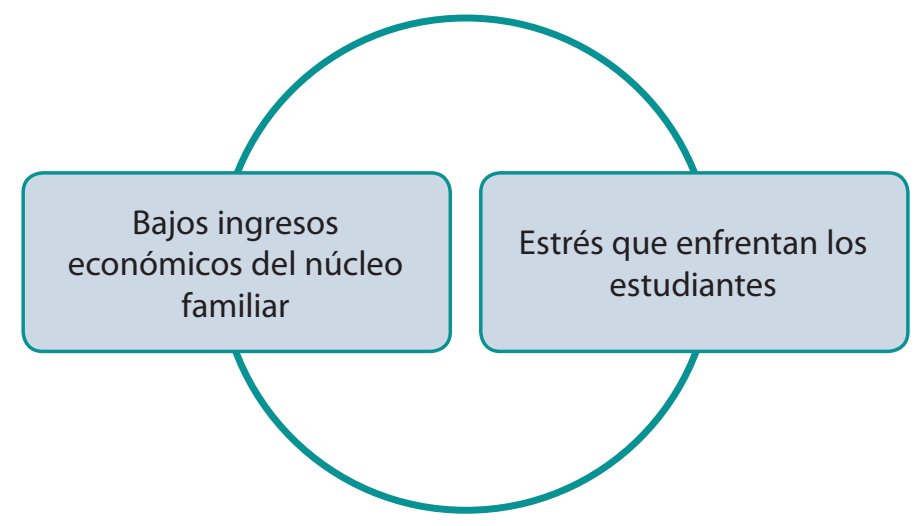

Figura 6. Factores económicos asociados a la deserción estudiantil según personal docente, administrativo, estudiantes y director. Colegio Nocturno La Unión, año 2012

Fuente: Herrera, 2012. Elaboración a partir de información suministrada en el Colegio Nocturno La Unión. 
El fin de la administración de la educación en cada organización es el cumplimiento de los objetivos propuestos por el centro educativo, de acuerdo con las necesidades de la comunidad en la cual se encuentra, por medio de la supervisión cuidadosa y detallada del administrador, en conjunto con la comunidad educativa. Al respecto, Chiavenato (1995) manifiesta que "la administración no es un fin en sí misma, pero sí un medio de lograr que las cosas se realicen de la mejor manera posible, al menor costo y con la mayor eficiencia y eficacia" (p. 13). La administración de la educación es el medio por el cual se logran alcanzar los objetivos definidos para responder a las demandas educativas de la sociedad, en unión de todos los integrantes de la organización.

\section{Factores familiares}

De la información obtenida por medio de las opiniones brindadas por los diferentes participantes en el estudio, se observa que el principal motivo familiar que influye en la deserción estudiantil en el Colegio Nocturno La Unión es el trabajar durante el día para ayudar con los gastos familiares, así como la poca motivación por parte de la familia para la realización de estudios.

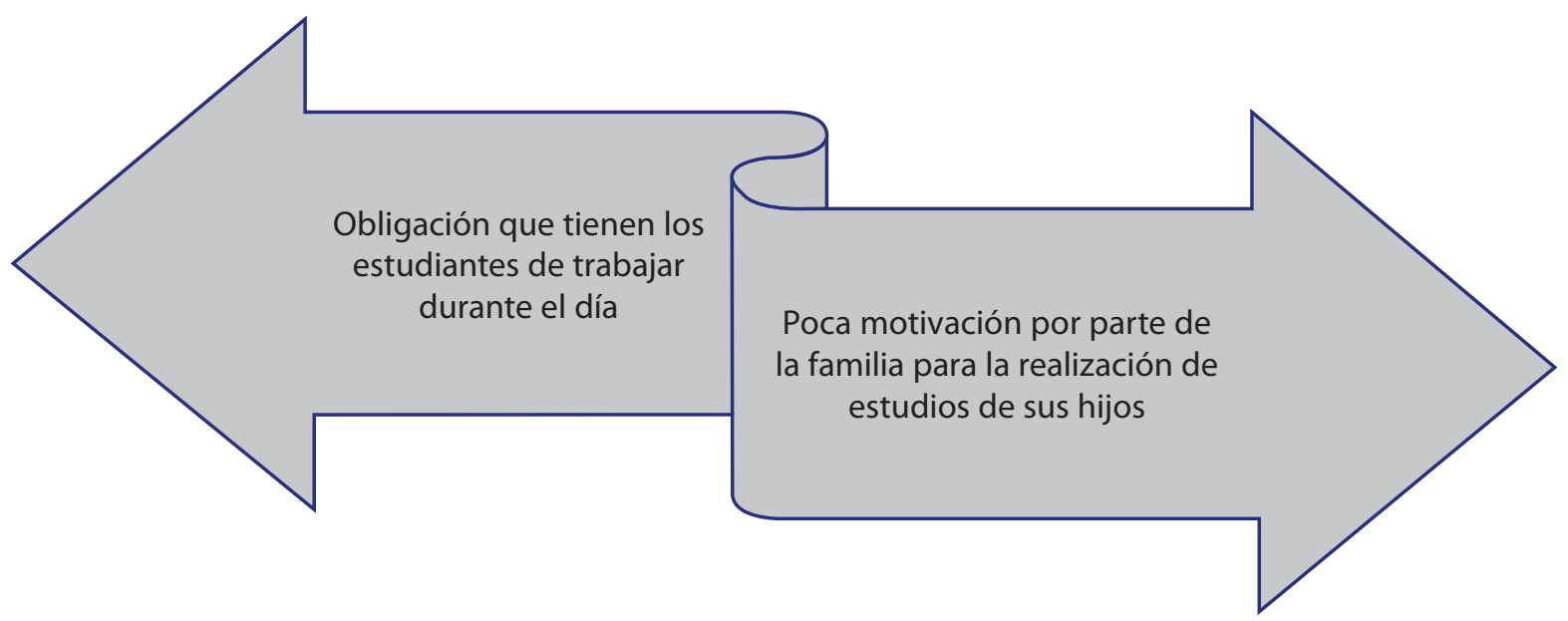

Figura 7. Factores familiares asociados a la deserción estudiantil según personal docente y administrativo, estudiantes y director. Colegio Nocturno La Unión, año 2012

Fuente: Herrera, 2012. Elaboración a partir de información suministrada en el Colegio Nocturno La Unión. 
En este sentido, Goicovic (2002) manifiesta que "uno de los argumentos más recurrentes para explicar la deserción escolar es el que relaciona este fenómeno con la adscripción temprana de los jóvenes al mundo del trabajo" (p. 13). Es claro, que una solución momentánea por parte de las familias que enfrentan problemas económicos es la inserción temprana al mercado laboral de los hijos, lo que los conlleva a dejar el sistema educativo, quedando imposibilitados de una educación que les brinde herramientas para enfrentar de mejor manera el futuro.

\section{Estrategias implementadas desde la administración del Colegio Nocturno La Unión para disminuir la deserción estudiantil}

El Colegio Nocturno de La Unión, dentro de las estrategias para enfrentar el abandono escolar, introduce los programas sociales que desarrolla el Ministerio de Educación Pública. En este sentido, es claro que el Programa Avancemos, es un Programa Social del Gobierno, donde intervienen varias instituciones, y es ejecutado por el IMAS, constituye un mecanismo valioso para afrontar la deserción escolar. Al respecto, CONARE (2011) señala que:

Los esfuerzos de retención han ido más allá de "Avancemos", como lo demuestran el programa "El cole en nuestras manos", ejecutado por el MEP desde el 2007 como un plan piloto para luchar contra la deserción y promover una cultura de paz en los centros educativos. La iniciativa involucra a los diferentes actores de la comunidad educativa en la creación de espacios extracurriculares, aprovechando el arte, el deporte, las actividades cívicas y la cultura como formas de educación social, que permitan el arraigo en el sistema, la identificación con la institución y la apropiación del entorno, a fin de potenciar el desarrollo de la identidad del joven. (p. 128)

Este programa, a escala nacional, ha contribuido a disminuir la tasa de deserción escolar; no obstante, es necesario hacer partícipes a los diferentes miembros de la comunidad educativa en la búsqueda de soluciones a este problema que afecta todavía a un importante número de centros educativos. 


\section{Información referente al Colegio Nacional Virtual Marco Tulio Salazar, sede en el cantón de La Unión}

\section{Tasa de deserción por nivel y género}

De acuerdo con la información suministrada por el Colegio Nacional Virtual Marco Tulio Salazar, sede en el cantón de La Unión, se presentaron altas tasas de deserción estudiantil en los diversos niveles, durante el curso lectivo 2011, por lo que es importante efectuar un análisis acerca de las posibles causas de este problema, que sin duda afecta a la comunidad educativa, este centro educativo únicamente se analizó el ciclo lectivo 2011, debido a que está institución surgió del Programa Nuevas Oportunidades, aprobado en el año 2000 por el Consejo Superior de Educación y que se consolida en abril del 2010.

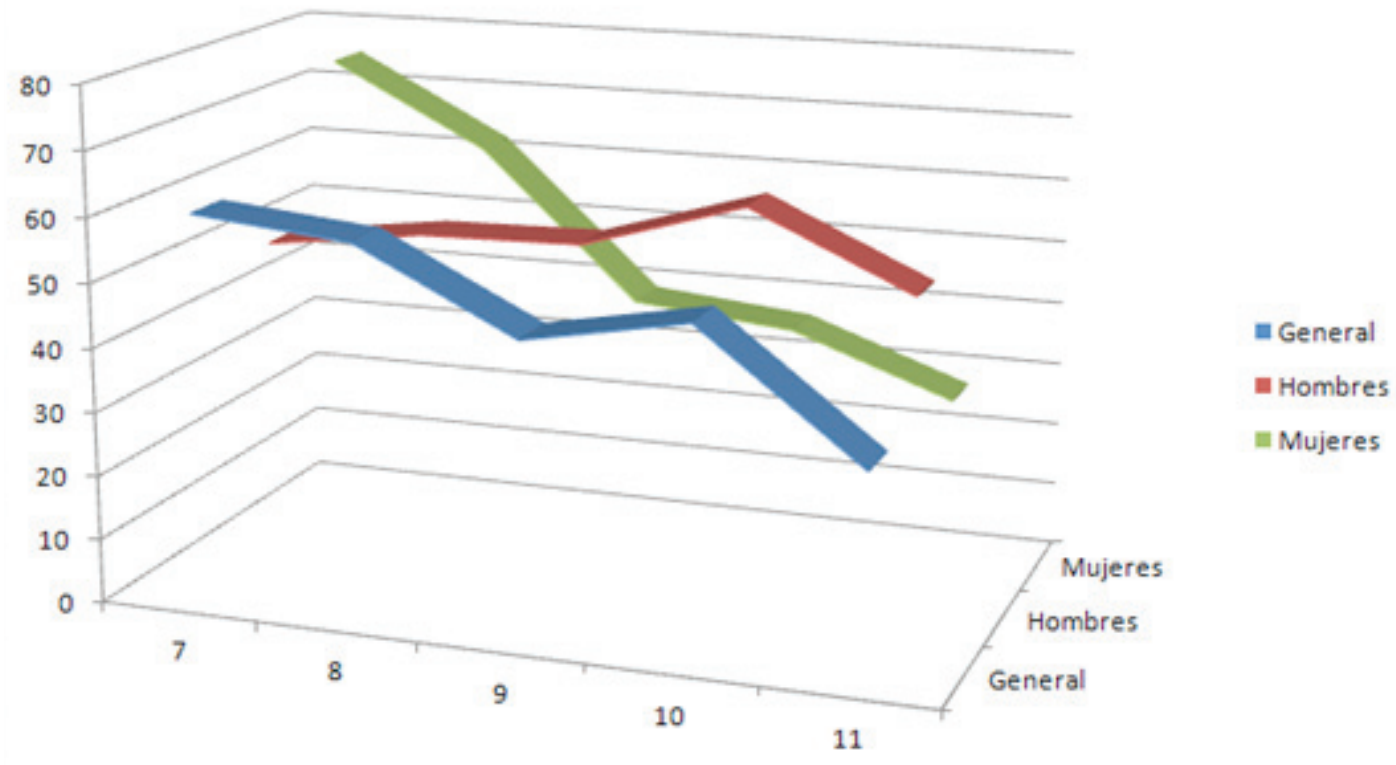

Figura 8. Deserción estudiantil, por género, Colegio Nacional Virtual Marco Tulio Salazar, sede en el cantón de La Unión, 2011

Fuente: Herrera, 2012. Elaboración a partir de información suministrada en el Colegio Nacional Marco Tulio Salazar, sede en el cantón de La Unión. 
Por medio de estadísticas se identifica que el nivel que presentó una mayor deserción en el ciclo lectivo 2011, es el de sétimo año y por género el porcentaje más alto de deserción con respecto a su matrícula inicial, fueron las mujeres de sétimo año, se identificaron los principales factores influyen en la deserción estudiantil y las estrategia que se deberán de implementar de acuerdo con las necesidades que presenta la población para enfrentar esta problemática, además de darle continuidad en los niveles posteriores.

\section{Factores que inciden en la deserción estudiantil}

\section{Factores socioculturales}

Con respecto a las opiniones del personal docente y administrativo, así como de la población estudiantil, coinciden que el indicador escaso seguimiento a los estudiantes con bajo rendimiento académico, es de gran influencia para que el estudiantado deserten del sistema educativo.

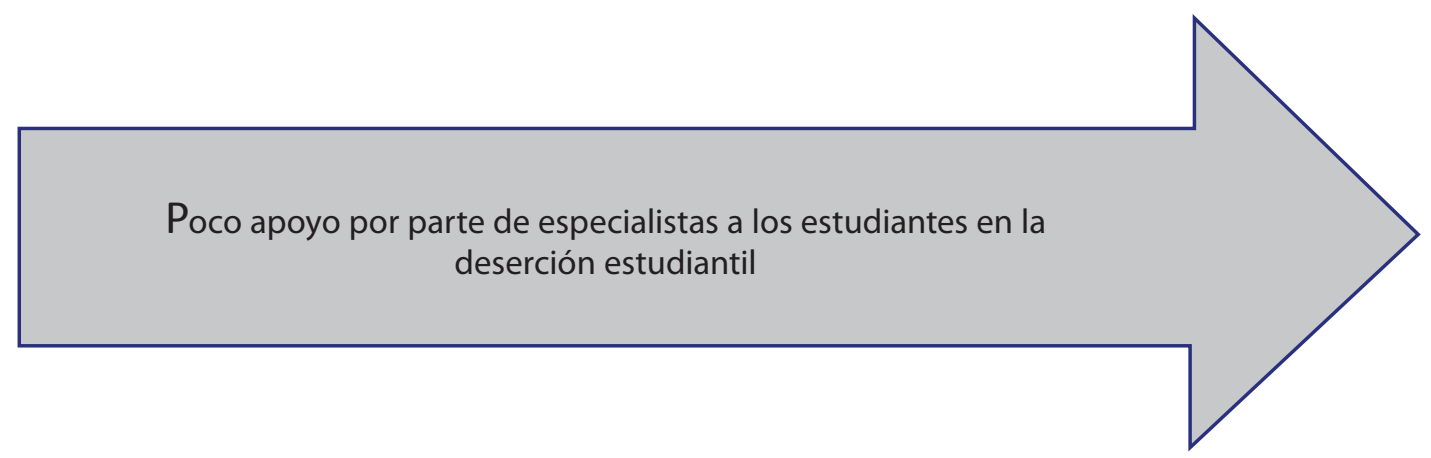

Figura 9. Factor sociocultural de deserción según personal docente y administrativo, estudiantes y director, Colegio Nacional Virtual Marco Tulio Salazar, sede en el cantón de La Unión, año 2012

Fuente: Herrera, 2012. Elaboración a partir de información suministrada en el Colegio Nacional Virtual Marco Tulio Salazar, sede en el cantón de La Unión.

Desde la dirección de la organización se debe apoyar la implementación de actividades académicas y recreativas diversas, con el objetivo de motivar y unir a los estudiantes, de manera que logren sentirse parte de la institución en la que se encuentran. En este sentido, Ruiz (2006) manifiesta que "el estudiante con rendimiento apenas regular o que fracasa escolarmente sufre en su autoestima y en la valoración de su pertenencia al sistema educativo" (p. 43). Al lograr identificar las principales causas de deserción estudiantil, el administrador de la institución, por 
medio de la integración de un comité que se dedique a tratar esta problemática, podrá aunar esfuerzos y dedicar recursos, dentro de las posibilidades existentes, para enfrentarla. Es claro que la incorporación del estudiante a las distintas actividades que se organicen dentro del centro educativo le permitirá aumentar su autoestima, además de que se sentirá identificado con la institución y motivado para continuar con sus estudios.

\section{Factores pedagógicos}

Al confrontar las opiniones brindadas por los diferentes participantes en el estudio, en lo que se refiere a las principales causas de tipo pedagógico que provocan deserción estudiantil en el Colegio Nacional Virtual Marco Tulio Salazar, sede en el cantón de La Unión, se observa que las respuestas coinciden al señalar como factores claves, falta de adecuación de métodos de enseñanza por parte de docentes, problemas de aprendizaje por parte de estudiantes y desactualización del currículo que se brinda en el centro educativo.
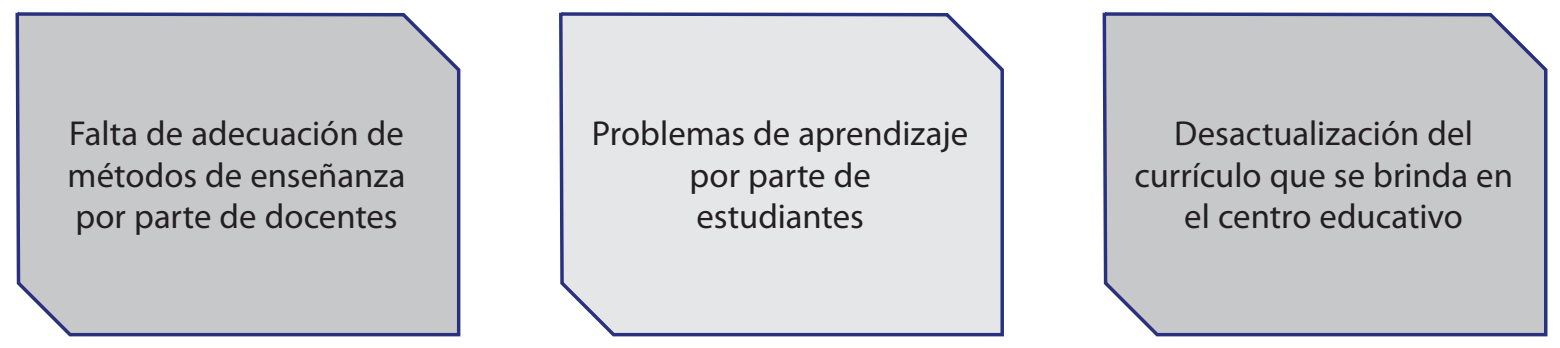

Figura 10. Factores pedagógicos de deserción según personal docente y administrativo, estudiantes y director, Colegio Nacional Virtual Marco Tulio Salazar, sede en el cantón de La Unión, año 2012

Fuente: Herrera, 2012. Elaboración a partir de información suministrada en el Colegio Nacional Virtual Marco Tulio Salazar, sede en el cantón de La Unión.

Como se evidencia en los resultados anteriores, es necesario que en el centro educativo se implementen diversas estrategias que permitan contrarrestar la deserción escolar; en conjunto, la dirección del centro educativo y el equipo docente deben realizar valiosos esfuerzos por brindar a los estudiantes una educación de calidad, que les permita afrontar los desafíos de la sociedad actual. Es importante que la población estudiantil se identifique con la institución donde realizan los estudios y valoren la necesidad de concluir con la formación que reciben, ya que esta constituye el medio que les permitirá salir adelante. Al respecto, Ruiz (2006) señala que: 
(...) gran parte de estos jóvenes encuentran tanto la escuela como el colegio sin sentido. La juventud costarricense dedica más de su tiempo en ver televisión, con amigos o incluso visitar centros comerciales, que lo que dedican a la lectura ni al estudio, y ni siguiera a los deportes. (p. 54)

\section{Factores económicos}

De acuerdo con las opiniones de los diferentes participantes en la investigación, con respecto a los principales motivos de índole económica que propician deserción estudiantil en el Colegio Nacional Virtual Marco Tulio Salazar, sede en el cantón de La Unión, se observa que las respuestas coinciden al señalar como indicadores claves: bajos ingresos económicos del núcleo familiar y desempleo por parte de estudiantes.

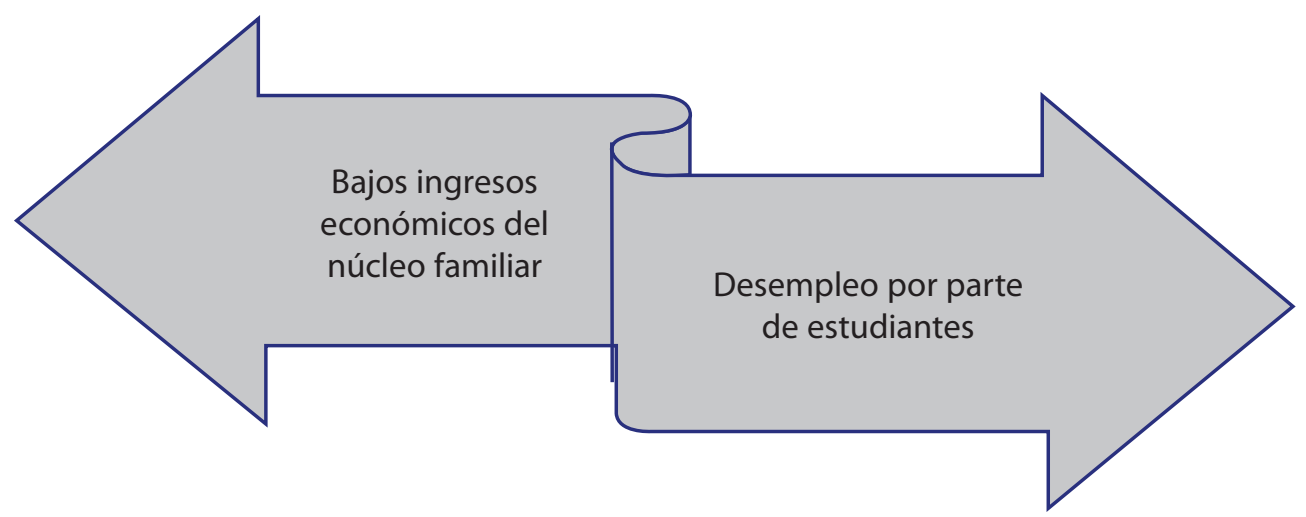

Figura 11. Factores económicos asociados con la deserción estudiantil según personal docente y administrativo, estudiantes y director, Colegio Nacional Virtual Marco Tulio Salazar, sede en el cantón de La Unión, año 2012

Fuente: Herrera, 2012. Elaboración a partir de información suministrada en el Colegio Nacional Virtual Marco Tulio Salazar, sede en el cantón de La Unión.

Desde la administración del centro educativo se deben emprender acciones, en las cuales se tome en cuenta a los actores de la comunidad educativa para enfrentar los factores de tipo económico que pueden provocar que los estudiantes dejen los estudios. En este sentido, Mackinney et al. (2006), referido por Arguedas y Jiménez (2007) manifiestan que:

La pobreza no solo significa limitaciones en lo económico y material, sino que es frecuente que se acompañe por desempleo, depresión, desesperanza, violencia y estrés. Por su parte, se ha encontrado que la salud y la nutrición son productoras del bajo rendimiento académico. (p. 8) 
Generalmente uno de los errores más comunes es considerar que la pobreza se encuentra únicamente en los aspectos económicos y material, dejando de lado todos los demás y que en muchas ocasiones no se les busca solución, la administración del centro educativo debe contemplar todos estos factores dentro de su plan para enfrentar la pobreza en sus estudiantes.

\section{Factores familiares}

El indicador, obligación de trabajar durante el día por parte de los estudiantes, es considerado como un indicador de gran influencia, por todos los participantes de la investigación, para la deserción estudiantil.

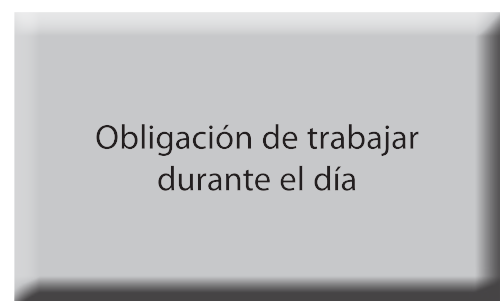

Figura 12. Factor familiar de deserción según personal docente y administrativo, estudiantes y director, Colegio Nacional Virtual Marco Tulio Salazar, sede en el cantón de La Unión, año 2012

Fuente: Herrera, 2012. Elaboración a partir de información suministrada en el Colegio Nacional Virtual Marco Tulio Salazar, sede en el cantón de La Unión.

De acuerdo con los datos suministrados por el personal docente y administrativo, así como el profesional en administración de la educación de la institución, se considera que la poca comunicación que suministran los familiares a los estudiantes, el poco apoyo, poca motivación y poca visión del futuro de sus hijos se asocia con los problemas económicos en que se encuentran (Arguedas y Jiménez, 2007). De esta manera, fundamenta los indicadores más influyentes en la deserción escolar, a los que se refiere Barrantes, citado por Álvarez, Arias, Cortés, Montiel, Rosales y Umaña (2006), cuando menciona que:

La familia, el nivel educativo de las madres y los padres y sus aspiraciones ocupacionales. No se trata de que no valores los beneficios de la educación, sino más bien que a lo largo de la bibliografía escolar no han captado con la oferta necesaria para enfrentar las dificultades que ha ido ocurriendo a lo largo del tiempo. (p. 7) 
Entre las finalidades de la administración de la educación el lograr el cumplimiento de los objetivos definidos por el centro educativo es de gran trascendencia; lo anterior mediante un trabajo de equipo, que conlleve un acompañamiento y continuidad.

\section{Estrategias implementadas desde la administración del Colegio Nacional Virtual Marco Tulio Salazar, sede en el cantón de La Unión, para disminuir la deserción estudiantil}

Al confrontar las opiniones brindadas por los diferentes participantes en el estudio, con respecto a las principales estrategias implementadas desde la administración del centro educativo para reducir la deserción estudiantil, se obtiene que la principal estrategia para enfrentar la deserción estudiantil es el apoyo que reciben los estudiantes que desean abandonar la institución por parte de la dirección de la institución.

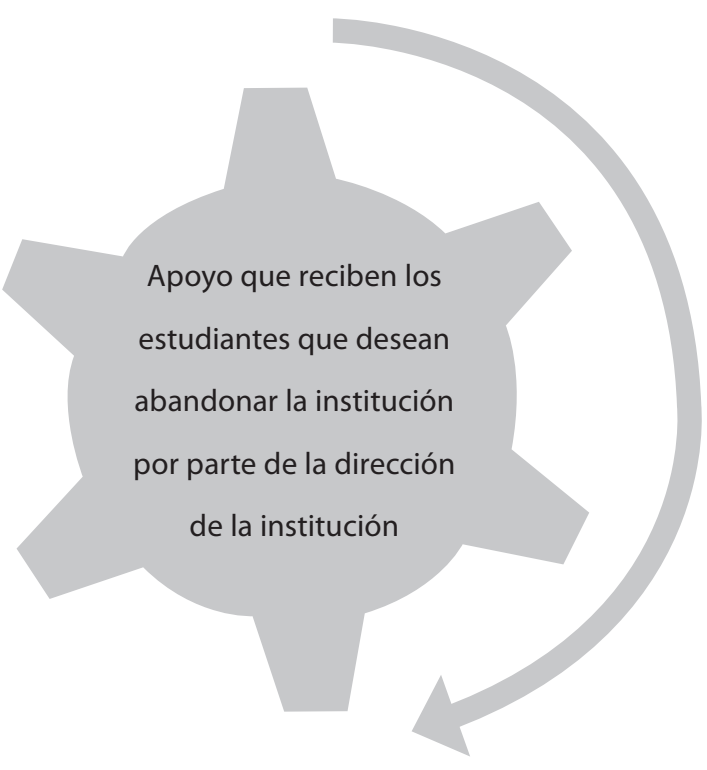

Figura 13. Estrategia implementada desde la administración del Colegio Nacional Virtual Marco Tulio Salazar, sede en el cantón de La Unión para enfrentar la deserción estudiantil

Fuente: Herrera, 2012. Elaboración a partir de información suministrada en el Colegio Nacional Virtual Marco Tulio Salazar, sede en el cantón de La Unión.

Cabe mencionar que, desde el 2007, entra en vigencia el Programa Avancemos con la finalidad de enfrentar la deserción escolar. De acuerdo con el Estado de la Educación, CONARE (2011): 
Los esfuerzos de retención han ido más allá de "Avancemos", como lo demuestran el programa "El cole en nuestras manos", ejecutado por el MEP desde el 2007 como un plan piloto para luchar contra la deserción y promover una cultura de paz en los centros educativos. La iniciativa involucra a los diferentes actores de la comunidad educativa en la creación de espacios extracurriculares, aprovechando el arte, el deporte, las actividades cívicas y la cultura como formas de educación social, que permitan el arraigo en el sistema, la identificación con la institución y la apropiación del entorno, a fin de potenciar el desarrollo de la identidad del joven. (p. 128)

El Programa Avancemos propuesto por el MEP, no es solo una beca de estudio, es un programa muy completo que abarca diferentes áreas culturales y sociales de los jóvenes estudiantes, con el principal objetivo de incentivarlos a no abandonar sus estudios.

\section{Conclusiones}

Luego del análisis de los datos recopilados en relación con las tasas de deserción escolar, las principales causas que generan este problema y las estrategias implementadas desde la administración para su prevención en el Colegio Nocturno La Unión y el Colegio Virtual Marco Tulio Salazar, sede en el cantón de La Unión, se pueden establecer las siguientes conclusiones:

De acuerdo con las estadísticas suministradas por el Colegio Nocturno La Unión y el Colegio Nacional Virtual Marco Tulio Salazar sede en el cantón de La Unión, se determinó que ambas instituciones coinciden en que el nivel de mayor deserción es el de sétimo año. Situación muy preocupante tanto para el administrador de la institución como para todos los demás miembros de las instituciones partícipes del estudio.

Por medio de un instrumento previamente estructurado, se identificaron las principales causas de los factores socioculturales, pedagógicos, económicos y familiares que contribuyeron en la deserción estudiantil, tanto para el Colegio Nocturno La Unión, como para el Colegio Nacional Virtual Marco Tulio Salazar, sede en el cantón de La Unión, dando la evidencia de las principales causas que desde la administración de la educación se deben trabajar por medio de diferentes estrategias, con el fin de motivar a los estudiantes de continuar con sus respectivos estudios de la forma más adecuada y consiente.

La segunda parte del instrumento consistió en recopilar información del impacto que realmente estaban presentando las estrategias aplicadas por los diferentes administradores de los centros educativos en estudio, los resultados coincidieron que el impacto no era el esperado, 
por lo que el instrumento suministra a los directores las estrategias que deben fortalecer con el objetivo de lograr el impacto deseado.

Desde la administración de los diferentes centros educativos, y en colaboración de los miembros de la institución, se deben implementar diferentes estrategias adecuadas con las necesidades de la comunidad y de los estudiantes, con el fin de disminuir la deserción estudiantil y lograr preparar seres humanos más íntegros, que al incorporase en la sociedad en un futuro próximo logren formar una sociedad más armoniosa.

De acuerdo con los resultados obtenidos en la presente investigación se le da fundamento a una propuesta de intervención para la deserción estudiantil desde la gestión del centro educativo.

\section{Referencias}

Álvarez, I. y Topete, C. (1998). El desafío de la calidad en la educación básica del futuro. Serie Foro Pedagógico N 19. México: Departamento de Reproducciones Gráficas de la SEP.

Álvarez, W, Arias, A; Cortés, C., Montiel, E., Rosales, X. y Umaña, M. (2006). Factores asociados a la deserción de la población estudiantil de sétimo año del Liceo José Martí, del Liceo de Chacarita y del Liceo Antonio Obando Chan en año 2004. (Tesis de Licenciatura). Universidad de Costa Rica. San José, Costa Rica.

Arguedas, I. y Jiménez, F. (2007). Factores que promueven la permanencia de estudiantes en la educación secundaria. Actualidades investigativas en educación, 7(3), 1-36. Recuperado de http://www.latindex.ucr.ac.cr/aie-2007-3/16-factores.pdf

Arroyo, J. A. (2010). Administración de la educación. Recuperado de http://www.slideshare.net/ Jarval/administracion-de-la-educacin-1671803

Chiavenato, I. (1995). Introducción a la teoría general de la administración (4ª ed.). Bogotá: McGrawHill.

Consejo Nacional de Rectores [CONARE]. (2010). Informe Estado de la Nación. Programa Estado de la Nación. San José, Costa Rica: Autor.

Consejo Nacional de Rectores [CONARE]. (2011). Informe Estado de la Educación. Programa Estado de la Nación. San José, Costa Rica: Autor.

Garbanzo, G. (2011). Administración y gestión escolar: una historia de concepciones y prácticas en disputa, una visión desde Centroamérica con énfasis en Costa Rica. Cuadernos de Investigación, 6(14). Recuperado de http://www.utp.br/Cadernos de Pesquisa/ 
Goicovic, I. (2002). Educación, deserción escolar e integración laboral juvenil. Revista Ultima década, 1(16), 11-53.

González, L. (2010). La Deserción escolar en el IPN de Silao de la Victoria, Guanajuato. Guanajuato, México: Editorial León.

Hernández, R., Fernández, C. y Baptista, P. (2006). Metodología de la investigación. México D.F.: McGRAW-HILL.

López, O. (2004). Sociología de la educación. San José., Costa Rica: EUNED.

Masís, C. (1989). Administración de instituciones o procesos educativos. San José., Costa Rica: EUNED.

Ministerio de Educación Pública (MEP). (1994). Política educativa hacia el siglo XXI. San José, Costa Rica: Autor.

Ministerio de Educación Pública (MEP). (2002). Plan de acción de la Educación para todos 20032015. San José, Costa Rica: Autor.

Ordóñez, J. (1999) Introducción a la Pedagogía. San José, Costa Rica: EUNED.

Organización de las Naciones Unidad para la Educación, la Ciencia y la Culrtura (UNESCO). (2011). Una crisis encubierta: conflictos armados y educación. Informe de seguimiento de la Educación para Todos en el mundo 2011. París: UNESCO.

Petit, K., Caliman, A. y Carvallo, B. (2009). Deserción escolar, proceso educativo y calidad de vida. Revista Especializada en Educación, 16(2), 335-347.

Ruiz, Á. (2006). Universalización de la educación secundaria y reforma educativa. San José, Costa Rica: EUCR.

Sánchez, Z., Ugalde, J., Vargas, W. y Venegas, P. (1984). El impacto de la crisis socioeconómica en la deserción del sistema educativo costarricense. Revista Educación, 8(1-2), 23-33.

Tristán, A. (2003). Elementos de educación de adultos: su aplicación en el ámbito judicial (2ª ed.). San José, Costa Rica: Editorial Poder Judicial.

Vásquez, E. (1985). Principios y técnicas de educación de adultos. San José, Costa Rica: EUNED.

Venegas, P. (1995). Innovación y cambio en educación: el director y el docente como participantes modulares. San José, Costa Rica: EUCR.

Zeledón, M. (2001). Los valores dentro de una gestión directiva eficaz. San José, Costa Rica: EUCR. 